\title{
Sistem Keamanan Smart Door Lock Menggunakan E-KTP (Elektroknik Kartu Tanda Penduduk) Berbasis Internet of Things (IoT)
}

\author{
Djayus Nor Salim*1, Neira Anjar Pujisusilo ${ }^{2}$, Samuel Pratama Manik ${ }^{3}$ \\ ${ }^{1}$ Program Studi Sistem Informasi, STMIK AUB, Surakarta, Indonesia \\ ${ }^{2,3}$ Program Studi Sistem Komputer, STMIK AUB, Surakarta, Indonesia \\ e-mail: *1djayus.nur@stmik-aub.ac.id, ${ }^{2}$ neira.anjr@gmail.com, \\ ${ }^{3}$ samuel.pratama180295@gmail.com
}

\begin{abstract}
Abstrak
Pintu merupakan sebuah media yang digunakan sebagai jalan untuk masuk atau keluar dari ruangan. Untuk mempermudah suatu pekerjaan dibutuhkan suatu alat yang efektif dan efisien. Tujuan dari penelitian ini adalah membuat sebuah sistem keamanan smart door lock menggunakan e-KTP berbasis Internet Of Things (IoT) dengan metode waterfall. Sistem keamanan smart door lock dibangun menggunakan RFID (Radio Frequency Identification) berbasis IoT dengan menggunakan mikrokontroler NodeMCU ESP32 dan dapat terkoneksi pada internet sehingga bisa diakses melalui smartphone android. Sistem keamanan smart door lock ini menggunakan RFID (Radio Frequency Identification) sebagai pembukanya dan juga dengan memanfaatkan teknologi Internet Of Things (IoT) dengan menggunakan wireless yang terhubung pada aplikasi smartphone android. Berdasarkan hasil penelitian ini adalah RFID (Radio Frequency Identification) yang digunakan memiliki keamanan yang lebih terjamin, karena yang mana untuk mendaftarkan e-KTP dengan menggunakan aplikasi Blynk pada smartphone android, jadi tidak semua orang bisa mendaftarkan e-KTP, dan juga terdapat buzzer akan mengeluarkan suara bip 1x apabila pintu dapat dibuka sesuai dengan frekuensi $13,56 \mathrm{MHz}$ yang terdapat dalam RFID yang dapat membaca e-KTP dengan jarak $50 \mathrm{~mm}$. Buzzer akan mengeluarkan suara bip $2 x$ apabila e-KTP tidak terdaftar pada alat tersebut. Solenoid Door Lock dapat membuka tuas pintu apabila e-KTP tidak sesuai dengan NodeMCU ESP32, solenoid akan mengunci kembali dalam waktu 2 detik. Kesimpulan dari penelitian yang dilakukan telah dirancang dan dibangun sistem keamanan smart door lock menggunakan e-KTP berbasis Internet Of Things (IoT).
\end{abstract}

Kata kunci-RFID (Radio Frequency Identification), Internet Of Things (IoT), e-KTP, Smartphone Android

\section{Abstract}

The door is a medium that is used as a way to enter or leave the room. To make a job easier, an effective and efficient tool is needed. The purpose of this research is to create a smart door lock security system using an e-KTP based on the Internet of Things (IoT) with the waterfall method. The smart door lock security system is built using IoT-based RFID (Radio Frequency Identification) using the NodeMCU ESP32 microcontroller and can be connected to the internet so that it can be accessed via an android smartphone. This smart door lock security system uses RFID (Radio Frequency Identification) as the opening and also by utilizing Internet Of Things (IoT) technology by using wireless connected to the android smartphone application. Based on the results of this study, the RFID reader used has more secure security, because which one to register an e-KTP using the Blynk application on an android smartphone, so not 
everyone can register an e-KTP, and there is also a buzzer that will emit a $1 x$ beep if the door can be opened according to the $13.56 \mathrm{MHz}$ frequency contained in the RFID which can read e$K T P$ with a distance of $50 \mathrm{~mm}$. The buzzer will emit 2 beeps if the e-KTP is not registered on the device. Solenoid Door Lock can open the door lever if the e-KTP is not compatible with NodeMCU ESP32, the solenoid will lock again within 2 seconds. The conclusion from the research conducted has been that a smart door lock security system has been designed and built using an Internet of Things (IoT)-based e-KTP.

Keywords-RFID (Radio Frequency Identification), IoT (Internet Of Things), e-KTP,
Smartphone Android

\section{PENDAHULUAN}

Perkembangan teknologi tidak hanya berpengaruh pada peralatan yang semakin canggih dan mutakhir tetapi juga berpengaruh pada budaya masyarakat [6]. Pengaruh teknologi terhadap manusia terlihat pada pola hidup yang bergantung dengan penggunaan smartphone android untuk membantu pekerjaan maupun memenuhi kebutuhan manusia. Contoh dari kegiatan yang dapat dilakukan dengan menggunakan smartphone android adalah berkomunikasi dengan orang lain, sebagai media hiburan, membeli kebutuhan sehari-hari dan kegiatan manusia yang lainya.

Untuk sistem keamanan pintu yang masih menggunakan kunci pintu yang kurang efisien dalam penggunaannya dikarenakan setiap hendak membuka maupun mengunci, pemilik masih sibuk mencari kunci. Padahal jika memanfaatkan perkembangan teknologi sekarang memungkinkan sistem keamanan pintu tanpa menggunakan kunci pintu.

Dari permasalahan tersebut, maka dibahas mengenai kendala lalu dipecahkan dengan menggunakan Internet Of Things (IoT). Kontrol sistem keamanan dapat langsung dilakukan dengan smartphone android yang dimiliki. Alat ini dibangun menjadi dua bagian yaitu hardware dan software. Pada hardware dibangun menggunakan mikrokontroler NodeMCU ESP32 yang dihubungkan langsung dengan solenoid door lock yang terdapat pada pintu melalui relay untuk mengatur high atau off pintu dan mikrokontroler NodeMCU ES32 dapat dikontrol dengan menggunakan smartphone android melalui internet. Pada bagian software dibangun menggunakan aplikasi Blynk pada smartphone android yang terhubung dengan mikrokontroler. Penelitian yang berjudul Rancang Bangun Sistem Keamanan Smart Door Lock Menggunakan eKTP (Elektronik Kartu Tanda Penduduk) dan Personal Identification Number Berbasis Arduino Mega R3 pada penelitian berjudul Rancang Bangun Sistem Keamanan Smart Door Lock Menggunakan e-KTP (Elektronik Kartu Tanda Penduduk) Dan Personal Identification Number Berbasis Arduino Mega R3 (Wendanto, dkk, 2019). Penelitian tersebut bertujuan untuk mengantisipasi pembobolan pintu rumah dan pencurian yang terjadi. Sistem keamanan dibangun menggunakan Arduino Mega R3 yang dihubungkan dengan modul relay sebagai saklar solenoid door lock. Hasilnya terciptanya sistem keamanan menggunakan e-KTP dan PIN dengan keypad $4 \times 4$. Perbedaan penelitian ini dengan penulis adalah penulis menggunakan mikrokontroler NodeMCU ESP32 yang sudah menggunakan wireless.

Untuk menyelesaikan permasalahan yang telah dijelaskan maka digunakan metode waterfall. Metode ini memungkinkan untuk pengembangan dan pengguna saling berinteraksi untuk membangun suatu sistem. Metode waterfall terdiri dari analisa kebutuhan, desain alat, penulisan kode program, pengujian program dan alat, dan pengoperasian alat yang ditanamkan pada mikrokontroler NodeMCU ESP32, dan evaluasi alat hingga mencapai tujuan yang dikehendaki.

\section{METODE PENELITIAN}

\subsection{Diagram Blok}


Untuk memudahkan perancangan dan pembuatan alat, maka dibuat diagram blok dari sistem secara keseluruhan. Berikut Gambar 1 diagram blok dari sistem keamanan pintu dan berbasis Internet of Things.

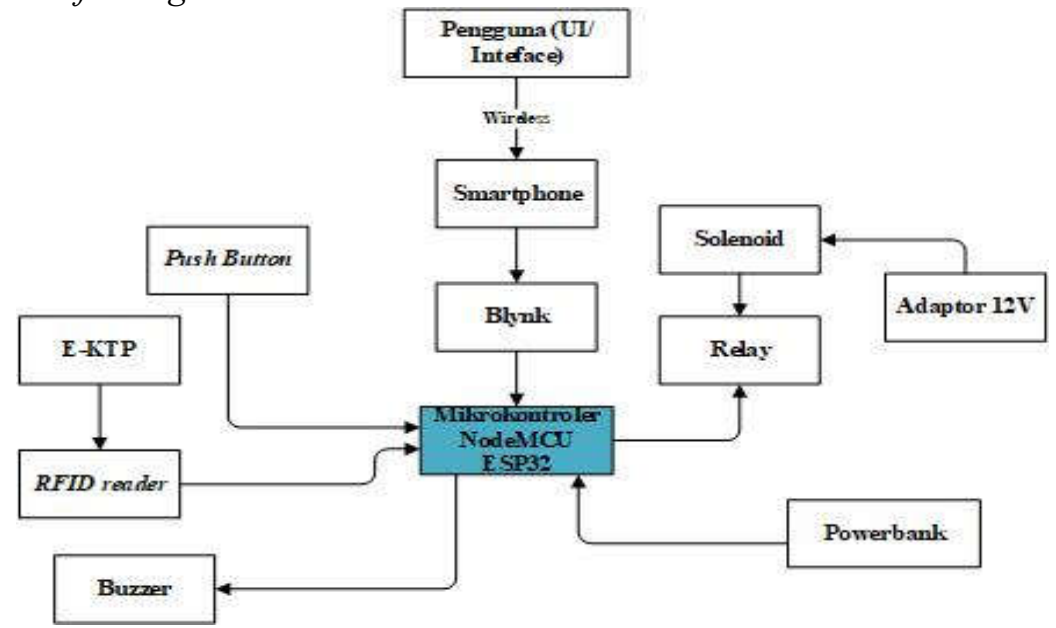

Gambar 1. Diagram Blok

\subsection{Tahap-Tahap Penelitian}

Berdasarkan dalam buku [4] model waterfall, garis besar penyelesaian masalah dalam penelitian ini terdapat 5 tahap meliputi:

a. Requirements Analysis (Analisa Kebutuhan)

Tahapan ini akan menghasilkan dokumen user requirement atau bisa dikatakan sebagai data yang saling berhubungan dengan keinginan user dalam pembuatan sistem.

b. System and Software Design (Desain Sistem)

Proses ini berfokus pada: struktur data, arsitektur perangkat lunak, representasi interface dan detail procedural. Tahapan ini akan menghasilkan dokumen yang disebut software requirement

c. Implementation and Unit Testing (Implementasi)

Tahapan ini merupakan tahapan secara nyata dalam mengerjakan suatu sistem. Dalam artian penggunaan komputer akan dimaksimalkan dalam tahapan ini.

d. Integration and System Testing (Pengujian Sistem)

Tujuan testing adalah menemukan kesalahan-kesalahan terhadap sistem tersebut dan kemudian bisa diperbaiki.

e. $\quad$ Operation and Maintenance (Pemeliharaan)

Tahapan ini bisa dikatakan final dalam pembuatan sebuah sistem. Setelah melakukan analisa, desain dan pengkodean maka sistem yang sudah jadi akan digunakan oleh user.

\subsection{Skema Perancangan Rangkaian}

Skema perancanganan rangkaian keseluruhan sistem digunakan pada sistem keamanan pintu dengan RFID meliputi rangkaian hardware terdiri dari NodeMCU ESP32 sebagai pusat kendali pada sistem keamanan pintu. Rangkaian hardware dapat dilihat pada Gambar 2. 


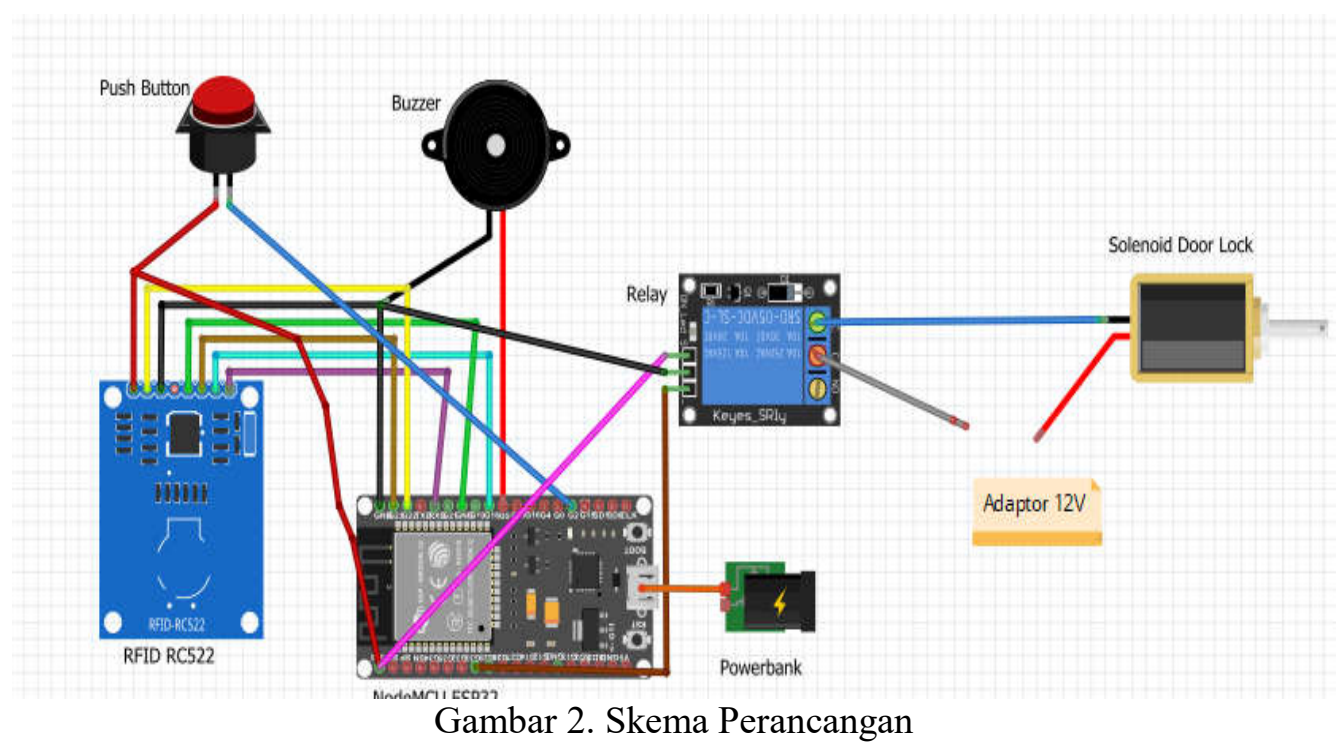

\subsection{Flowchart Sistem}

Pada Gambar 3 flowchart sistem keamanan pintu diawali dengan menghubungkan NodeMCU ESP32 dengan adaptor listrik. Lalu NodeMCU ESP32 akan menghubungkan sistem dengan jaringan wifi. Sistem keamanan pintu, jika sistem belum terhubung maka sistem akan terus menghubungkan dengan jaringan wifi yang terhubung. Setelah itu smartphone android harus menghubungkan lagi ke jaringan wifi. Setelah itu smartphone android masuk pada aplikasi Blynk, jika belum maka smartphone android harus masuk kembali pada Blynk hingga berhasil. 


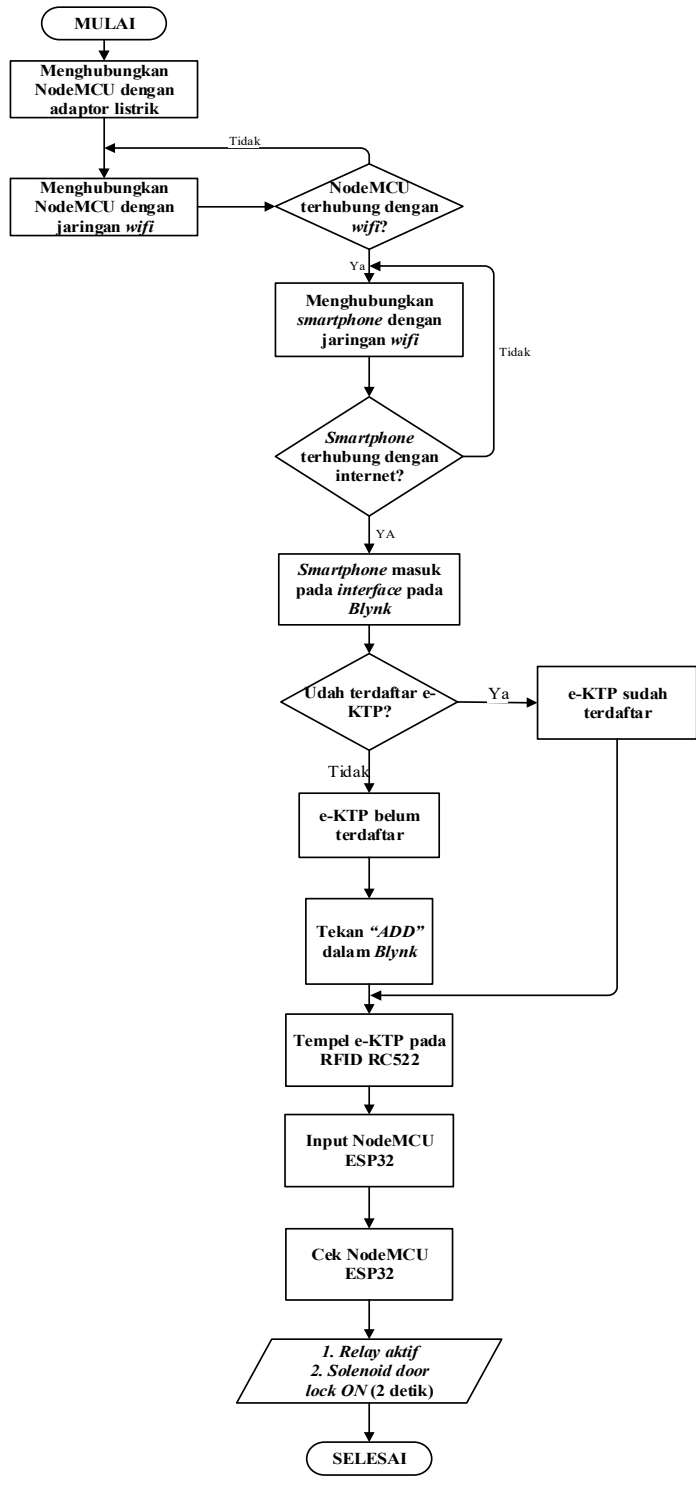

Gambar 3. Flowchart Menambah e-KTP

Gambar 3 Smartphone android yang berhasil masuk pada web server akan menampilkan interface sistem kendali pintu dengan RFID Lock. Setelah itu ketika e-KTP belum terdaftar maka perlu menambahkan ID kedalam NodeMCU ESP32. Langkah pertama tekan tombol dalam Blynk setelah itu tempel e-KTP pada RFID, maka input e-KTP yang akan didaftarkan akan diterima pada NodeMCU ESP32. NodeMCU ESP32 akan menyimpan data e-KTP yang sudah bisa digunakan. Lalu e-KTP yang sudah terdaftar dapat membuka pintu . Tempelkan eKTP pada RFID yang sudah didaftarkan maka NodeMCU ESP32 akan menerima input yang dikirim dari RFID, setelah itu NodeMCU ESP32 akan mengirim output pada relay dengan menghidupkan lampu LED warna hijau dan tuas solenoid akan memendek kedalam. Solenoid akan mengunci kembali dalam waktu delay 2 detik.

\subsection{Desain Blynk}

Blynk adalah platform sistem operasi iOS maupun Android sebagai kendali sebagai kendali pada modul Arduino [3]. Desain berikut merupakan sistem pengontrol yang terdapat dalam Blynk di smartphone, dapat dilihat pada Gambar 4 berikut. 


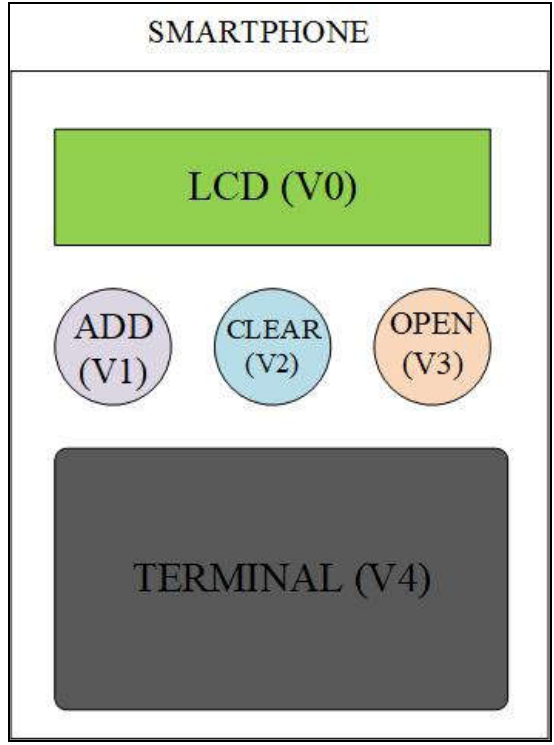

Gambar 4. Desain Blynk

\subsection{Desain IoT-LAN}

IoT (Internet of Thing) dapat didefinisikan kemampuan berbagai divice yang bisa saling terhubung dan saling bertukar data melalui jaringan internet [3] Desain IoT merupakan jarinagn LAN yang akan menghubungkan dari rangkaian hardware dan software. Dapat dilihat pada Gambar 5 berikut.

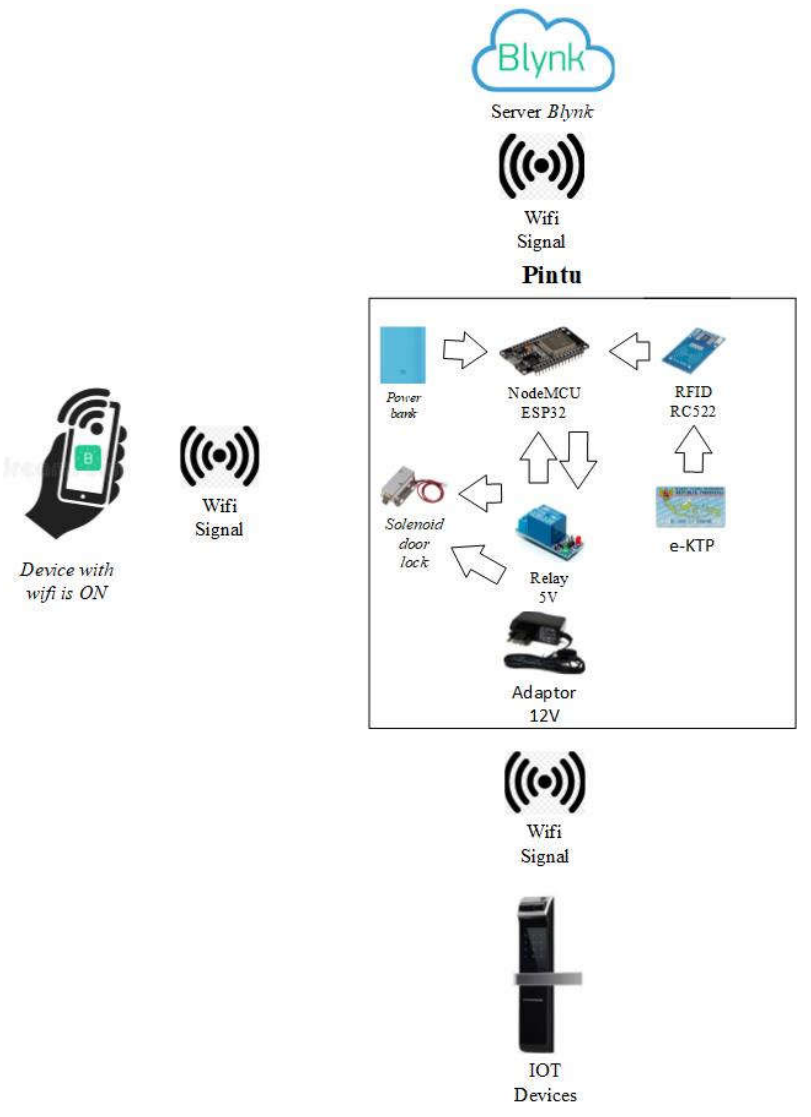

Gambar 5. Desain IoT-LAN 


\section{HASIL DAN PEMBAHASAN}

\subsection{Pengujian Kendali pada Blynk}

a. Tombol $A D D$

Pada saat tombol $A D D$ ditekan maka akan muncul tampilan seperti pada Gambar 6 dan Gambar 7 Tampilan Tombol $A D D$ berfungsi untuk menyimpan ID pada e-KTP.

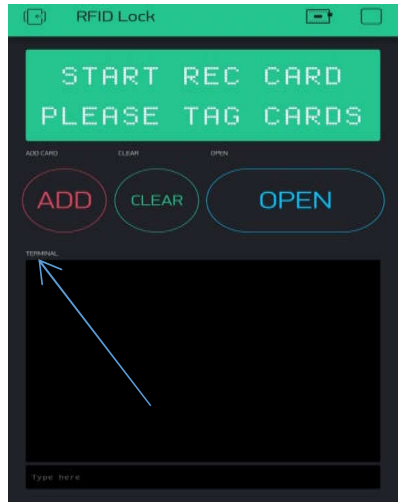

Gambar 6. Tampilan Tombol $A D D$

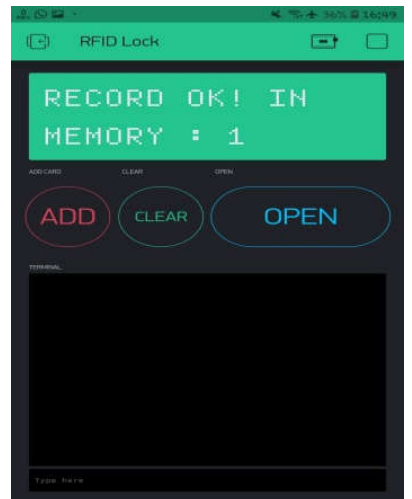

Gambar 7. Tampilan ID sudah terdaftar

b. Tombol CLEAR

Pada Gambar 8 dan Gambar 9 adalah tampilan pada terminal saat banyak ID yang menggunakan sistem Kemanan, jika tampilan terminal sudah terisi penuh maka bisa membersihkan semua ID yang telah menggunakan sistem keamanan.

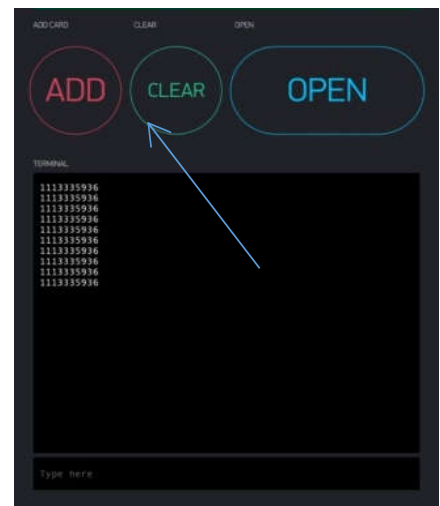

Gambar 8. Tampilan Tombol CLEAR

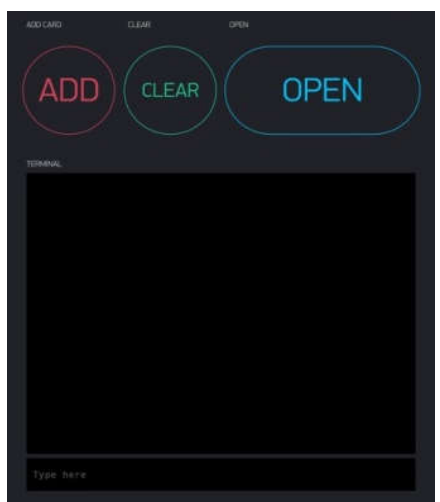

Gambar 9. Terminal sudah terhapus

c. Tombol OPEN

Pada Gambar 10 dan Gambar 11 adalah tampilan pada saat pengguna menekan tombol $O P E N$ pada aplikasi, maka akan muncul tampilan akses pintu kunci terbuka.

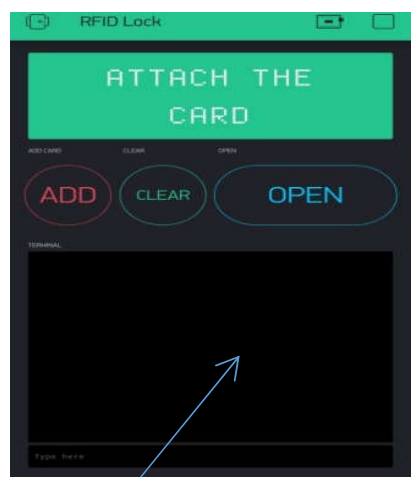

Gambar 10. Tampilan Tombol OPEN

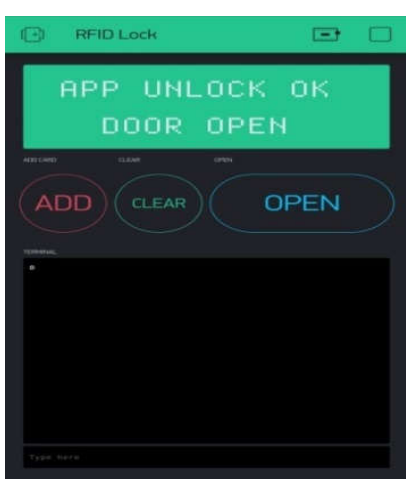

Gambar 11. Berhasil membuka Pintu 
d. Tampilan ID terdaftar dan tidak terdaftar

Pada Gambar 12 dan Gambar 13 adalah tampilan saat ID e-KTP sudah terdaftar dan ID eKTP tidak terdaftar.

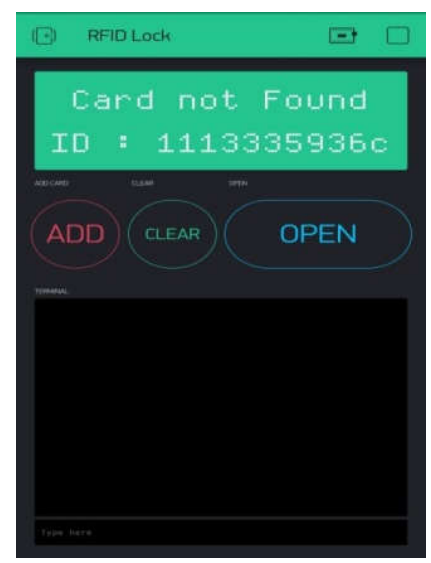

Gambar 12. Tampilan e-KTP belum terdaftar

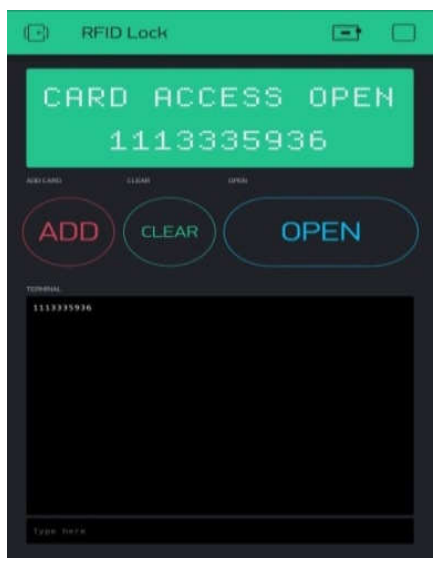

Gambar 13. Tampilan e-KTP sudah terdaftar

\subsection{Pengujian Sistem dalam jarak 10-50 mm}

Tabel 1. Pengujian Sistem Keamanan jarak 10-50mm

\begin{tabular}{|c|c|c|c|c|}
\hline Percobaan & Jarak (mm) & Delay (detik) & Relay & Solenoid \\
\hline 1 & 10 & 2 & $\begin{array}{c}\text { LED Lampu } \\
\text { Hijau }\end{array}$ & $\begin{array}{c}\text { Tuas solenoid tertarik } \\
\text { kedalam }\end{array}$ \\
\hline 2 & 20 & 2 & $\begin{array}{c}\text { LED Lampu } \\
\text { Hijau }\end{array}$ & $\begin{array}{c}\text { Tuas solenoid tertarik } \\
\text { kedalam }\end{array}$ \\
\hline 3 & 30 & 2 & $\begin{array}{c}\text { LED Lampu } \\
\text { Hijau }\end{array}$ & $\begin{array}{c}\text { Tuas solenoid tertarik } \\
\text { kedalam }\end{array}$ \\
\hline 4 & 40 & 2 & $\begin{array}{c}\text { LED Lampu } \\
\text { Hijau }\end{array}$ & $\begin{array}{c}\text { Tuas solenoid tertarik } \\
\text { kedalam }\end{array}$ \\
\hline 5 & 50 & 2 & $\begin{array}{c}\text { LED Lampu } \\
\text { Hijau }\end{array}$ & $\begin{array}{c}\text { Tuas solenoid tertarik } \\
\text { kedalam }\end{array}$ \\
\hline
\end{tabular}

Pada Tabel 1 menampilkan data pengujian sistem secara keseluruhan, dimana diawali dengan pengujian e-KTP kearah RFID. Jarak yang diuji dari 10-50 $\mathrm{mm}$ dan hasilnya semua tuas lock aktif/tertarik kedalam saat terdeteksi dan kembali ke posisi semula/mengunci setelah delay 2 detik.

\subsection{Pembahasan}

Dalam Pembahasan sistem keamanan ini menggunakan e-KTP sebagai kunci pintu, berdasarkan jurnal [3] bentuk e-KTP sesuai dengan ISO 14443 format seukuran kartu kredit yaitu 53,98 $\mathrm{mmx} 85,60 \mathrm{~mm}$. Penyimpanan data di dalam chip sesuai dengan standar internasional NISTR 7123 dan Machine Readable Travel Documents ICAO 9303 serta EU passport specification 2006. Berdasarkan buku panduan ISO/IEC 7810:2003 kartu dengan standar ISO/ICE 7810 merupakan kartu identifikasi yang termasuk dalam golongan smart card sama dengan kartu dengan standar ISO/IEC 14443 yang dapat digunakan sebagai identification card. Dari beberapa artikel dan jurnal tersebut dapat disimpulkan bahwa e-KTP dapat digunakan sebagai kunci pintu dengan frekuensi $13.56 \mathrm{Mhz}$ yang termasuk dalam kunci pintu jenis HF (High Frekuensi). 


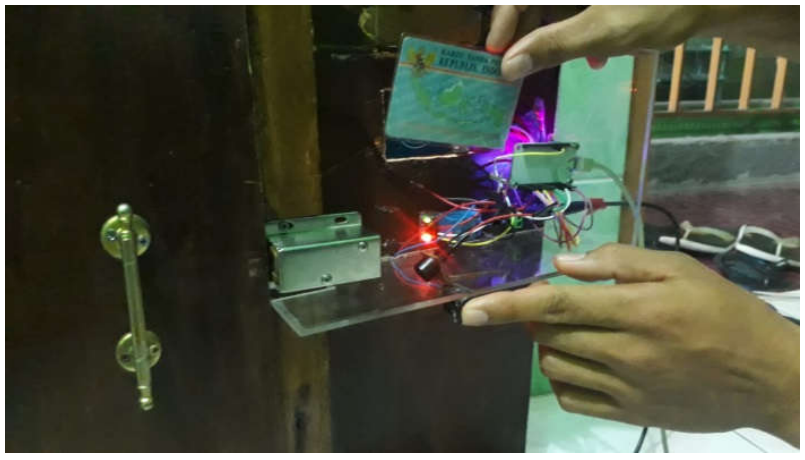

Gambar 14. Menempelkan e-KTP pada RFID

Pada Gambar 14 hasil proses pengujian RFID RC522 pada sistem keamanan pintu menggunakan e-KTP yang diletakkan didalam triplek dengan ketebalan $1 \mathrm{~cm}$ dapat membaca eKTP dengan jarak maksimal $50 \mathrm{~mm}$. Setelah dilakukan pengujian, NodeMCU ESP32 akan mengirim sinyal kepada relay dan relay akan mengirim sinyal kepada solenoid door lock yang dapat menjadi pengunci pintu rumah ketika e-KTP yang didekatkan atau ditempelkan dapat dibaca RFID RC522 dan nomor ID dapat diakses oleh mikrokontroler yaitu pada jarak maksimal $1 \mathrm{~cm}$.

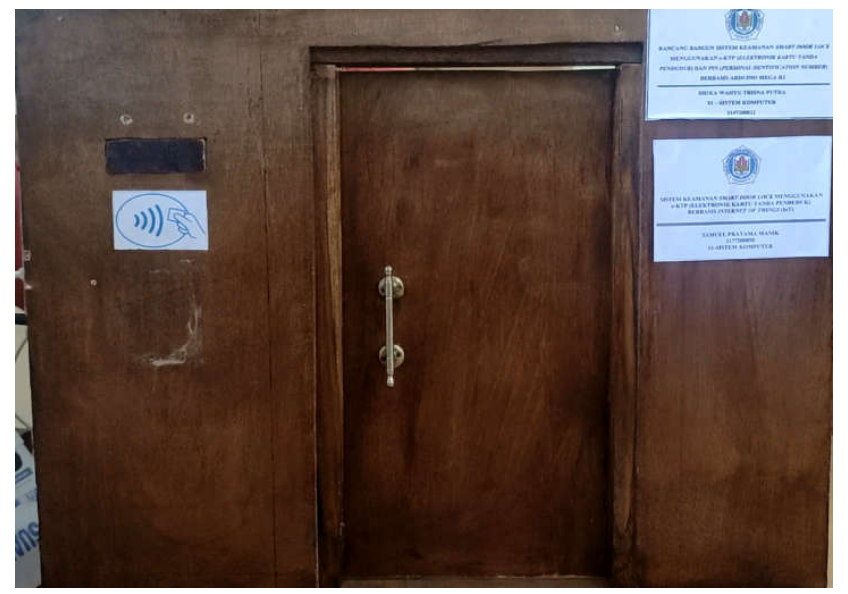

Gambar 15. Tampilan dari luar dan tempat scan e-KTP

Pada gambar 15 menjelaskan cara penggunaan alat siistem keamanan dari depan pintu pertama kali adalah dengan menempelkan menempelkan e-KTP yang sudah terdaftar di samping pintu pada bagian yang sudah disediakan RFID RC522. Bila verifikasi e-KTP berhasil maka NodeMCU ESP32 akan mengirim sinyal buka pada relay yang akan menghidupkan lampu led berwana hijau dan solenoid door lock akan terbuka. Solenoid dooor lock akan mengunci kembali dengan delay 2 detik.

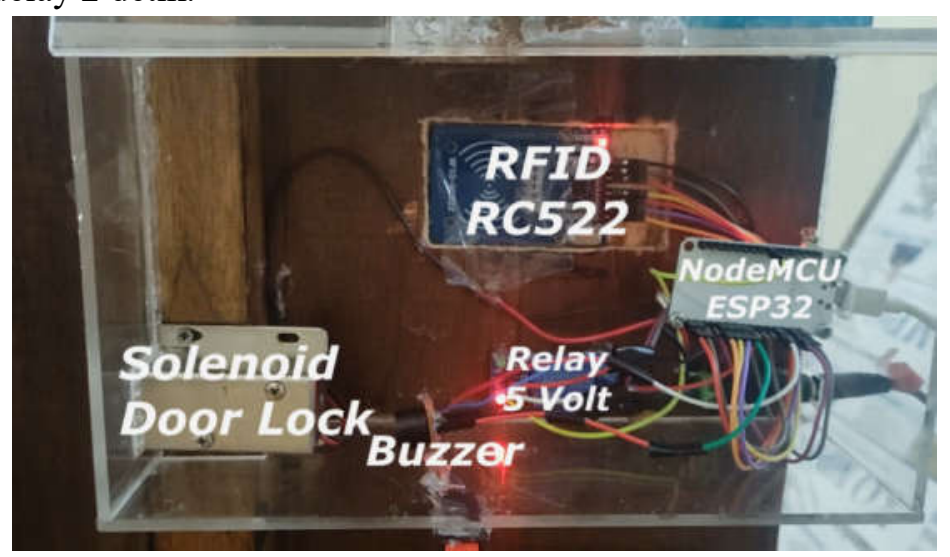

Gambar 16. Komponen keseluruhan 
Pada Gambar 16 untuk membuka pintu dari dalam cukup dengan menekan tombol Push Button yang terdapat dibagian bawah komponen berwana merah maka solenoid akan aktif high sehingga kunci pintu membuka.

\section{KESIMPULAN}

Dari penelitian ini dapat disimpulkan penyelesaian masalah membuka dan mengunci pintu dengan solusi membuat sistem keamanan dengan e-KTP sebagai pengganti kunci pintu yang jika ditempelkan pada RFID, solenoid akan terbuka dan mengunci kembali dengan delay 2 detik. Telah dibangun "Sistem keamanan Smart Door Lock menggunakan Elektronik Kartu Tanda Penduduk (e-KTP) berbasis Internet Of Things (IoT)". Sistem keamanan menggunakan NodeMCU ESP32, RFID sebagai sensor pembaca ID dalam e-KTP, Solenoid Door Lock sebagai pengunci pintu, Blynk pada Smartphone android.

\section{SARAN}

Dalam pembuatan alat ini masih terdapat kekurangan baik dari software, hardware maupun jaringan, oleh karena itu untuk pengembangan lebih lanjut diberikan saran penambahan perangkat power daya cadangan yang lebih besar dan dapat diisi ulang secara realtime, sebagai contoh aki yang berfungsi sebagai tenaga cadangan dikala listrik atau PLN padam serta penambahan item barcode scanner berfungsi agar dapat mengakses sistem keamanan selain mengggunakan aplikasi yang sudah dibuat.

\section{UCAPAN TERIMA KASIH}

Terima kasih kepada Ketua Program Studi dan selaku Kepala Laboratorium, karena telah memberikan kesempatan kepada peneliti untuk mengembangkan alat sistem keamanan pada peneliti terdahulu atas nama Dhika Wahyu T.P.

\section{DAFTAR PUSTAKA}

[1] Aryani D, Iskandar D. Indriyanti F. (2018). Perancangan Smart Door Lock Menggunakan Voice Recognition Berbasis Raspberry PI 3. ISSN : 2461-1417, Vol 4 No 2, 180-89.

[2] Asad M.R, Nurhayati O.D. Widianto E.D. (2016, Januari). Sistem Pengamanan Pintu Rumah Otomatis Via SMS Berbasis Mikrokontroler ATMega328P. Jurnal teknologi dan Sistem Komputer, Vol.3, No.1, 1-7.

[3] Gondohanindijo J, 2016. KTP Elektronoik (e-KTP) Bagi Penduduk Indonesia, Majalah Ilmiah Informatika Vol 3 No.1, Januari 2016H

[4] Hamami K, Muhsim M \& Siswanto D, 2020. Prototipe Sistem Monitoring Biaya Penggunaan Listrik Pada Rumah Kost Berbasis IoT. JASEE Journal of Application and Science on Electrical Engineering. Vol 1 No. 2. Hal 100-110 September 2020

[5] Javed, B., Iqbal, M. W., \& Abbas, H, 2017. Internet of Things (IoT) Design Considerations for Developers and Manufacturers. International Workshop on Smart Communication Protocols and Algorithms

[6] Pressman R. S, 2012. Rekayasa Perangkat Lunak - Buku Satu ,Pendekatan Praktisi ANDI (Edisi 7). Yogyakarta: ANDI.

[7] Ramadhan M.A, Noertjahjono S. Wahyuni F.S. (2020). Rancang Bangun Akses Kunci Pintu Gerbang Indekos Menggunakan E-KTP (Elektronik Kartu Tanda Penduduk) Berbasis Mikrokontroler. JATI (Jurnal Mahasiswa Teknik Informatika), Vol. 4 No. 2, 239-246.

[8] Setiawan A \& Purnamasari A.I. (2019). Pengembangan Smart Home Dengan Microcontrollers ESP32 Dan MC-38 Door Magnetic Switch Sensor Berbasis Internet of 
Things (IoT) Untuk Meningkatkan Deteksi Dini Keamanan Perumahan. Jurnal RESTI (Rekayasa Sistem dan Teknologi Informasi), Vol. 3 No. 3, 451-457.

[9] Suneki, S. (2012). Dampak Globalisasi Terhadap Eksistensi Budaya Daerah. Jurnal Ilmiah CIVIS, Volume II, No 1, Januari 2012, 2, 307-321.

[10] Weldi, Triyanto D, Ristian U, 2020. Aplikasi Sistem Kontrol Portal Parkir Menggunakan Metode Lock GPS Berbasis Internet Of Things . Coding : Jurnal Komputer dan Aplikasi Vol 08 No. 032020 hal 40-49

[11] Wendanto, W., Salim, D.J.N, \& Putra, D.W, 2019 Rancang Bangun Sistem Keamanan Smart Door Lock Menggunakan E-KTP (Elektronik Kartu Tanda Penduduk) Dan Personal Identification Number Berbasis Arduino Mega R3, Go Infotech: Jurnal Ilmiah STMIK AUB, Vol 25 No.2, Desember 2019

[12] Wicaksono, M. F. (2017). Implementasi Modul Wifi Nodemcu Esp8266 Untuk Smart Home. Jurnal Teknik Komputer Unikom, 6(1), 1-6. 